\title{
A Transient Method for Determining Thermal Diffusivity of Tobacco Stems *
}

by

\author{
N. N. Barthakur
}

Department of Renewable Resources, Macdonald College of McGill University,

Ste. Anne de Bellevue, Quebec, Canada

and

N. P. Arnold

Experimental Farm, Agriculture Canada, L'Assomption, Quebec, Canada

\section{SUMMARY}

A microwave generator and a closed-circuit wind tunnel were used to measure the thermal diffusivity of tobacco (Nicotiana tabacum L.) stems in vivo by the unsteady-state method. A simple mathematical model for heat flow, based on Fourier's heat-conduction equation and Newton's law of cooling, was used in this study. The microwave method was found to be relatively rapid as both heating and cooling of a cylindrical stem in an air stream could be completed in approximately 30 minutes for thermal-diffusivity determinations. Thermal-diffusivity value of the tobacco stems, containing $94 \%$ moisture and a mean stem temperature of $30^{\circ} \mathrm{C}$, was found to be $(1.38 \pm 0.06) \times 10^{-7} \mathrm{~m}^{2} \mathrm{~s}^{-1}$. The coefficient of variation for the measurements did not exceed $1.4 \%$ as determined through the analysis of cooling curves for five different air-flow rates over the stems. This study showed that the microwave technique could be effectively used to determine both accurately and reliably the thermal diffusivity of tobacco stems in vivo.

\section{ZUSAMMENFASSUNG}

Das Temperaturleitvermōgen der Rippen des Tabakblattes (Nicotiana tabacum L.) wurde im Windkanal mit umlaufendem Luftstrom unter nichtstationären Bedingungen mittels Mikrowellengenerator in vivo untersucht. Zur Bestimmung des $\mathbb{W}$ ärmeflusses diente ein

\footnotetext{
* Received: 8th August 1988 - accepted: 2nd February 1989.
}

einfaches, auf der Grundlage der Fourierschen Wärmeleitungsgleichung und des Newtonschen Kältegesetzes entwickeltes mathematisches Modell. Es zeigte sich, daß die Anwendung der Mikrowellentechnik verhältnismäßig wenig Zeit beansprucht, da sich die zylindrische Blattrippe zwecks Ermittlung der Temperaturleitfähigkeit in dem Zeitraum von ungefähr 30 Minuten in einem Luftstrom erwärmen und abkühlen läßt. Das Temperaturleitvermögen von Tabakrippen mit einem Feuchtigkeitsgehalt von $94 \%$ und einer Temperatur von durchschnittlich $30^{\circ} \mathrm{C}$ betrug $(1,38 \pm 0,06) \times$ $10^{-7} \mathrm{~m}^{2} \mathrm{~s}^{-1}$. Aus den Meß̧werten der fūr fünf verschiedene Luftströmungsgeschwindigkeiten erstellten Abkühlungskurven ergab sich ein Variationskoeffizient von unter $1,4 \%$. Die Untersuchungsergebnisse zeigen, $\mathrm{daß}$ sich die 'T'emperaturleitfāhigkeit von Tabakrippen unter Einsatz der Mikrowellentechnik verläßlich und genau in vivo bestimmen läßt.

\section{RESUME}

La diffusivité thermique des côtes de la feuille de tabac (Nicotiana tabacum L.) a été étudiée in vivo, dans des conditions non stationnaires, à l'aide d'une soufflerie en circuit fermé et d'un générateur de micro-ondes. Un modèle mathématique simple, développé sur la base de l'équation de conduction de la chaleur de Fourier et de la loi newtonienne de refroidissement a été utilisé pour la détermination du flux thermique. Il est apparu que la technique des micro-ondes permettait de procéder en relativement peu de temps, puisque 30 minutes environ ont suffi pour échauffer et refroidir la côte cylindrique de la feuille dans un courant d'air aux fins de l'expé- 
rience. la diffusivité des côtes de tabac ayant une teneur en humidité de $94 \%$, à la température moyenne de $30^{\circ} \mathrm{C}$, s'élève à $(1,38 \pm 0,06) \times 10^{-7} \mathrm{~m}^{2} \mathrm{~s}^{-1}$. L'analyse des courbes de refroidissement obtenues pour cinq vitesses différentes de circulation de l'air, a révélé que le coefficient de variation des mesures n'excédait pas $1,4 \%$. Les résultats de cette étude montrent ainsi que la technique des micro-ondes permet de déterminer in vivo, avec précision et fiabilité, la diffusivité thermique des côtes des feuilles de tabac.

\section{INTRODUCTION}

The importance of thermophysical properties of food and agricultural materials has been emphasized by researchers involved in thermal processing and curing of these products $(1,2,3,4,5,6)$. Thermal properties are also important when living biological materials are subjected to heat treatment by flaming for pest control purposes on field crops and for increasing the percent germination of seeds (5).

If the heat application is to be effective for the intended objective, then time-temperature relationships become critical. When temperature changes with time, thermaldiffusivity property of a material can be used to predict how fast heat travels through the material. Thermal diffusivity is the ratio of thermal conductivity to the product of bulk density and specific heat of the material.

Thermal conductivity, the ratio of a heat flux to the corresponding temperature gradient, can be determined by a steady-state method which requires the measurements of these quantities. Thermal conductivity and specific heat of tobacco during the curing process has been determined using the guarded hot-plate method (7). With this technique, the thermal diffusivity can be calculated from the measured conductivity and heat capacity if the bulk density of the material is also known.

Thermal diffusivity has the dimensions of

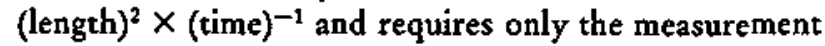
of time for heat to travel a known distance. Length and time can be measured more easily and precisely than thermal fluxes and temperature gradients (8). Thus, direct experimental determination of thermal diffusivity is expected to be more accurate and less time-consuming than the indirect method of calculation based on thermal conductivity, heat capacity, and bulk density.

Attempts to determine the thermal diffusivity of cut tobacco leaves were found to be error prone because of shredding (9). A sharp increase in thermal-diffusivity values at low moisture content indicated that the variation in the compressibility of the tobacco was a major contributing factor to the large uncertainty in thermaldiffusivity measurements by this method. Although thermal diffusivity for liquid nitrogen-preserved alfalfa stems have been successfully determined (10), no technique has yet been developed for measuring thermal diffusivity of a whole living plant rooted in soil.
A microwave generator, in combination with a closedcircuit wind tunnel, was found suitable in the laboratory of the senior author to study thermal-response characteristics of live plants and also to investigate thermal diffusivity of apples $(11,12,13)$. These studies indicated the microwave method to be simple, rapid and reliable. The objective of this paper is to extend this technique to determine thermal diffusivity of tobacco stems in vivo.

\section{MATERIALS AND METHODS}

Seeds of Delgold tobacco (Nicotiana tabacum L.) were sown in flats containing Pro-mix on 25 November, 1987 , and the seedlings grown in a greenhouse according to provincial recommendations (14). On $10 \mathrm{Febru-}$ ary, 1988, seedlings were transplanted to $15 \mathrm{~cm}$ plastic pots containing Pro-mix supplemented with $20 \mathrm{~g}$ of 16-10-10 NPK fertilizer and the plants kept in the greenhouse for an additional two weeks. The plants were then transferred to a closed-circuit wind tunnel in which the experiments were conducted. Details of the wind tunnel and the microwave generator were published elsewhere (15). Prior to the heat treatment, all leaves were removed from the plant with a sharp blade and vaseline was applied lightly to the freshly cut surfaces to prevent evaporation.

Plant stems selected for the experiments averaged $1.2 \mathrm{~cm}$ in diameter and $16 \mathrm{~cm}$ in length. Based on these dimensions, the stems were considered to be infinite cylinders because stem length " $b$ " was considerably greater than its diameter " $2 R$ " $[b / 2 R \gg 1](16)$. The basal end of a stem was considered insulated as it remained immersed in the potted soil mix. Thus, heat transfer between the cylinder surface and the surrounding air could occur only radially over the entire lateral surface, and the temperature of the cylinder would therefore depend on time and radius.

Stem and ambient temperatures were measured by $0.035 \mathrm{~cm}$ diameter copper-constantan thermocouples. Sensors for stem and air temperatures were placed on the cylinder axis and at $2.5 \mathrm{~cm}$ from the cylinder surface, respectively. Temperatures were continuously recorded, and as soon as the stem attained an elevated steady-state temperature of $44^{\circ} \mathrm{C}$ under $75 \mathrm{~W}$ incident power, the radiation treatment was discontinued, and the stem was allowed to reach a new equilibrium temperature.

Three cooling curves for each air-flow rate on three different plants were analyzed and the resulting values of thermal diffusivity were averaged and reported.

\section{Theoretical Model}

The basis for the mathematical description of heat flow in a body has been the Fourier's heat-conduction equa-

\footnotetext{
* Les Tourbières Premier Ltée., Rivière-du-Loup, Quebec.
} 
tion which can be expressed in the cylindrical co-ordinate system for one-dimensional flow as (16):

$$
\begin{array}{r}
\partial T / \partial t=D\left[\partial^{2} T / \partial r^{2}+(2 / r) \partial T / \partial r\right], \\
t>0 ; 0<r<R
\end{array}
$$

where

$$
\begin{aligned}
T(r, t) & =\text { stem temperature as a function of } r \text { and } t \\
r & =\text { radial position, } \\
t & =\text { time, } \\
D & =\text { thermal diffusivity. }
\end{aligned}
$$

The pertinent boundary conditions for the present experiments are given in equations 2 to 4-as follows:

$$
\begin{gathered}
T(r, 0)=f(r) \\
\partial T(0, t) / \partial r=0 \\
T(0, t) \neq \infty \\
d T / d t=-h\left(T-T_{a}\right) .
\end{gathered}
$$

Initially, the infinite cylinder has a radial temperature distribution in the form of the function $f(r)$. There is no temperature gradient at any point on the cylinder axis which is taken as the $\mathrm{z}$-axis; the temperature along the axis during the entire heat-transfer process must also be finite according to equation 3. Equation 4 is an expression of Newton's law of cooling, where $h=$ heattransfer coefficient and $T_{2}=$ ambient temperature.

The series solution of equation 1 under the given boundary conditions can be written as $(3,16)$ :

$$
\begin{aligned}
U(r, t) & =\left[T(r, t)-T_{2}\right] /\left(T_{i}-T_{2}\right) \\
& =\sum_{n=1}^{\infty} C_{n} \exp \left[-\left(\mu_{n} / R\right)^{2} D t\right], \\
J_{0}\left(\mu_{n}\right) B i & -\mu_{n} J_{1}\left(\mu_{n}\right),
\end{aligned}
$$

where

$U(r, t)=$ normalized dimensionless temperature ratio as a function of $\mathrm{r}$ and $\mathrm{t}$,

$\mathrm{T}_{\mathrm{i}} \quad$ = initial uniform temperature of body,

$\mu_{n} \quad=n$th root of the transcendental equation 6 for an infinite cylinder,

$C_{n} \quad$ - function of $\mu_{n}$, geometry, and position within the body but independent of time or temperature,

$\mathrm{Bi}-$ Biot number $=h \mathrm{R} / \mathrm{k}$,

k - thermal conductivity,

$\mathrm{J}_{0}\left(\mu_{\mathrm{a}}\right)=$ zero-order Bessel function of the first kind,

$\mathrm{J}_{1}\left(\mu_{n}\right)$ - first-order Bessel function of the first kind.

Equation 5 can be used if six restrictions imposed on the experimental object and the medium are met (3): [a] The object must be homogeneous and isotropic. Since the dry-matter distribution in each $16 \mathrm{~cm}$ tobacco stem is almost completely uniform from tip to base, any existing heterogeneity would only be very small and can be neglected for our purpose. The high moisture content of the stems ( $94 \%$ ) ensures a degree of homogeneity and isotropicity necessary for these experiments.

[b] The solid must have an analytically describable shape. This condition is satisfied as previously discussed.

[c] The initial temperature of solid must be uniform. The initial temperature $\left(44^{\circ} \mathrm{C}\right)$ acquired by a tobacco stem is attributed to the dielectric heating mechanism of microwaves. As the major dielectric component in a stem is water which is uniformly distributed in the stem, the energy is therefore absorbed throughout the stem without directly altering the thermal state of air in the wind tunnel.

[d] The heat-transfer coefficient ${ }^{\text { }} \mathrm{h}$ " must be constant with time. The " $h$ " value depends on size and shape of the solid, and the environmental parameters. As these factors remain constant, the heat-transfer coefficient will also remain constant with time.

[e] The temperature of the medium must be constant with time. The controlled environment of the tunnel maintained the air-temperature constant with time.

[f] The thermal properties of the material must be constant with time and temperature. The problem of the movement of water from hot to cold regions inside experimental objects has been encountered by previous authors (5) who used methods that required prolonged heating and cooling periods. The thermal properties of the tobacco stems are not expected to vary with time and temperature because of the rapid, dielectric heating of microwaves.

Since all the above conditions have been met, the theory of heat flow for an infinite cylinder can now be applied to tobacco stems undergoing transient heat exchange with the surrounding air. When an object cools, the time-temperature relationship at a certain stage becomes exponential and a simplified form of equation 5 can be used by retaining only the first term of the series which is written as (3):

$$
\begin{aligned}
U(r, t) & =\left[T(r, t)-T_{2}\right] /\left(T_{i}-T_{2}\right) \\
& =C_{1} \exp \left[-\left(\mu_{1} / R\right)^{2} D t\right], \\
\ln U(r, t) & =-\left(\mu_{1} / R\right)^{2} D_{t}+\ln C_{1} .
\end{aligned}
$$

Equation 8 shows that semi-logarithmic plot of the temperature ratio versus time should be a straight line and its slope is given by:

$$
\text { Slope }=-\left(\mu_{1} / R\right)^{2} D \text {. }
$$


The slope can be calculated from any two points on the straight line from equation 10 :

$$
\text { Slope }=\left[\ln U\left(r, t_{1}\right)-\ln U\left(r, t_{2}\right)\right] /\left(t_{1}-t_{2}\right) .
$$

Thus, thermal diffusivity can be determined from equations 9 and 10 if the value of " $\mu_{1}$ " is known. Equation 6 is used to find $\mu_{1}$ if " $\mathrm{Bi}$ " can be evaluated. The first step is to calculate " $h$ " by using the integrated form of Newton's law of cooling given in equation 11 as:

$$
\ln \left[\left(T-T_{2}\right) /\left(T_{i}-T_{a}\right)\right]=-(h A / M S) t,
$$

where

$M$ - mass of stem,
$S$ - specific heat,

$A=2 \pi R b=$ lateral surface area.

The " $h$ " value and thermal conductivity for water were used to estimate $\mathrm{Bi}=\mathrm{h} \mathrm{R} / \mathrm{k}$. The " $\mathrm{Bi}$ " values were increased by blowing air over the stems.

A relationship between $\mu_{1}$ and Bi for infinite cylinders is given in equation $12(3,16)$ :

$$
\mu_{1}^{2}=\left(\mu_{1}\right)_{\infty}^{2}\left[1+I(B i)^{-c}\right]^{-1},
$$

where $\left(\mu_{1}\right)_{\infty}$ is the limiting value of $\mu_{1}$ as $B i$ approaches infinity. When $B i$ approaches infinity, $\left(\mu_{1}\right)_{\infty}=2.4048$, $c=1.04$, and $I=2.45$. The $\mu_{1}$ values were calculated from equation 12 and were substituted in equation 9 to determine $\mathrm{D}$ for tobacco stems.

\section{RESULTS AND DISCUSSION}

Semi-logarithmic plot of time-temperature data for the tobacco stems showed a pronounced linear portion at all wind velocities (Fig. 1). Deviations from linearity were observed towards the beginning and the end of the cooling period. Stem temperature at time zero deviated from linearity whereas the deviation was considerable towards the other extremity of the cooling curve as a stem approached a new equilibrium temperature.

The shape of the cooling curve can be explained by the manner in which a stem exchanges heat with the environment. Heat transfer to the surrounding air may be the principal mechanism of cooling during the linear part of the semi-logarithmic time-temperature curve. Both heat and mass-transfer mechanisms could be involved as stem cooling progressed towards a new state of thermal equilibrium. Cuticular transpiration and absorption of water by the roots may play a part in cooling behaviour towards the end of the time-temperature curve. Absorption of water from soil lags behind the water loss due to transpiration as slight water deficits occur frequently in most plants (17), and this might explain the delayed effect of mass transfer on the cooling curves. The present results were not affected as only the linear portions of the cooling curves were used in the determination of $D$ values.

The results (Table 1) showed a small increase in thermal-diffusivity values with increased wind velocity, heat-transfer coefficient, $\mu_{1}$, and $\mathrm{Bi}$. More than a threefold increase in heat-transfer coefficient caused only about $12 \%$ increase in the $D$ value of the stems. The average $D$ value was $(1.38 \pm 0.06) \times 10^{-7} \mathrm{~m}^{2} \mathrm{~s}^{-1}$. This can be compared with the $\mathrm{D}$ of water at $32.2^{\circ} \mathrm{C}$ which was reported as $1.495 \times 10^{-7} \mathrm{~m}^{2} \mathrm{~s}^{-1}$ (18). The lower $\mathrm{D}$ value for tobacco stems could be attributed to the drymatter content.

Thermal diffusivity is a function of temperature and moisture content. While the average moisture content of the stems was found to be $94 \%$, a temperature should also be mentioned in order for the $D$ value to be meaningfully used. A mean cylinder temperature $T$ is defined by the triple integral of equation 13 :

$$
T=1 /\left(\pi R^{2} b\right) \int_{0}^{R} \int_{0}^{2 \pi} \int_{0}^{b} T(r, t) r d r d \Theta d z,
$$

where $r, \Theta$, and $z$ are the cylindrical co-ordinates. The integral can be evaluated if temperature is known as a

\section{Figure 1.}

Seml-logarlthmic plot of time-temperature data for different wind velocitles which are indlcated beaide curves $\ln \mathrm{m} \mathrm{s}^{-1}$.

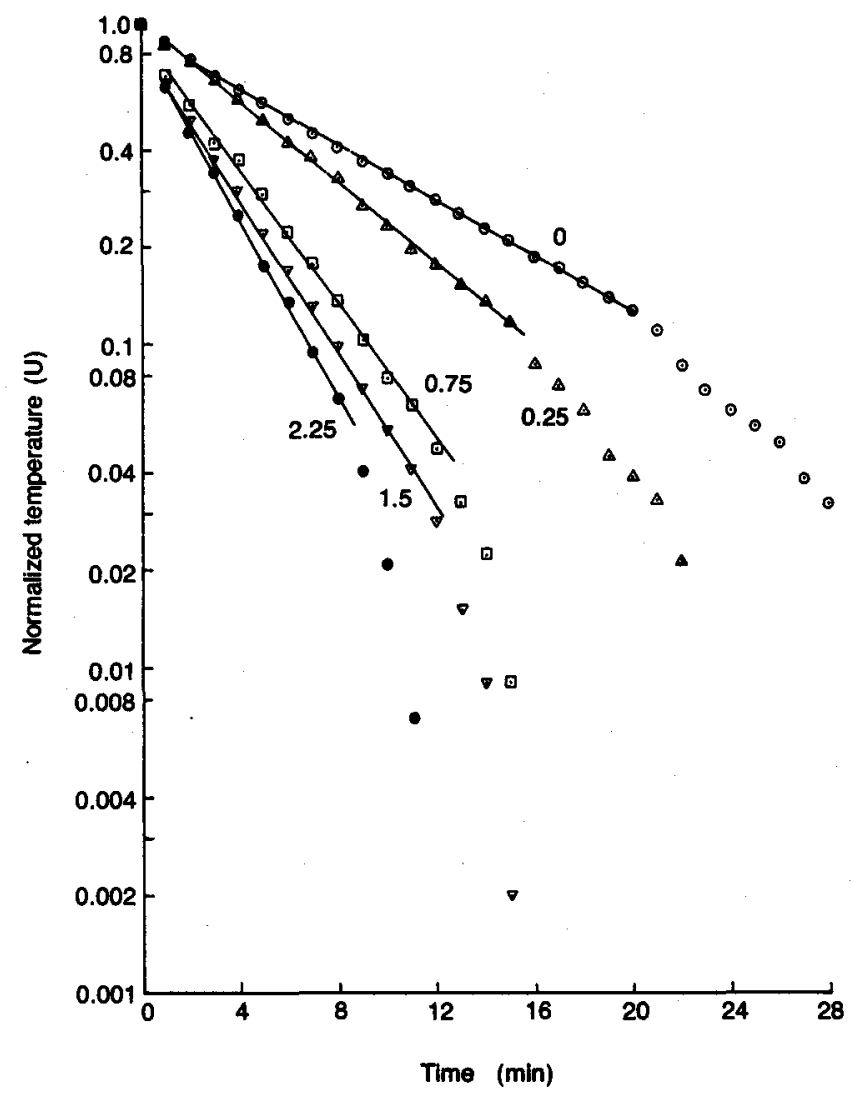


Table 1.

Thermal diffusivity of tobacco stems.

\begin{tabular}{l|c|c|c|c|c}
\hline $\begin{array}{c}\text { Wind } \\
\text { velocity } \\
\left(\mathrm{m} \mathrm{s}^{-1}\right)\end{array}$ & $\begin{array}{c}\mathrm{h} \pm \text { S.D. } \\
\left(\mathrm{J} \mathrm{m}^{2} \mathrm{~s}^{-1} \mathrm{o}^{-1}\right)\end{array}$ & $\mu_{1}$ & $\mathrm{Bi}$ & $\begin{array}{c}\mathrm{D} \pm \mathrm{S} . \mathrm{D} . \\
\left(\mathrm{m}^{2} \mathrm{~s}^{-1} \times 10^{7}\right)\end{array}$ & Coeff. of var. * \\
\hline 0 & $19.0 \pm 1.5$ & 0.66 & 0.22 & $1.31 \pm 0.015$ & 1.2 \\
0.25 & $27.4 \pm 1.3$ & 0.79 & 0.31 & $1.33 \pm 0.015$ & 1.1 \\
0.75 & $42.7 \pm 4.4$ & 0.96 & 0.48 & $1.40 \pm 0.020$ & 1.4 \\
1.50 & $51.3 \pm 2.4$ & 1.05 & 0.59 & $1.41 \pm 0.015$ & 1.1 \\
2.25 & $63.3 \pm 1.0$ & 1.14 & 0.72 & $1.47 \pm 0.020$ & 1.4 \\
\hline
\end{tabular}

- Coefficient of variation $=$ (standard deviation / mean $) \times 100$.

function of time and radius. In view of the small temperature gradient in stem interior $(0.22 \leqq \mathrm{Bi} \leqq 0.72)$, we estimated $\mathrm{T}$ by assuming temperature to be a function of time only as given by Newton's law of cooling in equation 11. Substitution of equation 11 in equation 13, yielded a value of $30^{\circ} \mathrm{C}$ as the mean temperature of the stems used in this experiment. $\mathrm{Bi}$ was found to be much smaller than 10 but greater than 0.2 . The range of the above $\mathrm{Bi}$ values indicated that temperature gradient between the cylinder centre and its surface was small in our experiments. However, the temperature difference between the cylinder surface and the surrounding medium was considerable. If $\mathrm{Bi}$ is very small (less than 0.2 ), the temperature of the sample is expected to be uniform (5). If $\mathrm{Bi}$ is large (more than 10), the temperature difference between cylinder surface and the surrounding medium is negligible and a large temperature gradient must exist between centre and surface.

The merit of the present experimental approach lies in the rapidity and simplicity with which thermal diffusivity of tobacco stems in vivo can be measured. The entire time-temperature data necessary for a single measurement could be obtained in about 30 minutes. This compares favourably with respect to previous methods which were time-consuming and elaborate $(7,8,9)$. The small coefficients of variation observed in the measurements of D (Table 1) also showed that the method has excellent repeatability. Another distinctive feature of the microwave method is the manner in which heat losses can be handled. The heating time by microwaves is shorter than when conventional methods are used; thus, both the thermal effect on biological organisms and heat losses should be minimized because of the reduced time of measurements.

The results of this study suggest that the microwave technique can be used for thermal-diffusivity measurements of plants in vivo. Experiments are in progress in this laboratory to investigate thermal diffusivity of tobacco at low moisture content, covering a wide range of temperature by this method. The method requires uniform heating and accurate temperature measure- ments, which may limit the usefulness of commercial microwave ovens designed for cooking purposes for thermal-diffusivity determinations.

\section{REFERENCES}

1. Rao, M. A., J. Barnard and J. F. Kenny: Thermal conductivity and thermal diffusivity of process variety squash and white potatoes; Trans. ASAE 18 (1975) 1188-1192.

2. Hayakawa, K., and J. Uno: A method for estimating thermal diffusivity of heat conduction food in a cylindrical can; J. Food Sci. 45 (1980) 692-695.

3. Gaffney, J. J., C. D. Baird and W. D. Eshleman: Review and analysis of the transient method for determining thermal diffusivity of fruits and vegetables; ASHRAE Trans. 86 (1980) 261-280.

4. Ramaswamy, H. S., and M. A. Tung: Thermophysical properties of apples in relation to freezing; J. Food Sci. 46 (1981) 724-728.

5. Mohsenin, N. N.: Thermal properties of foods and agricultural materials; Gordon and Breach Science Publishers, New York, N.Y., 1980.

6. Singh, P. R.: Thermal diffusivity in food processing; Food Technol. 36 (1982) 87-91.

7. Duncan, G. A., J. M. Bunn and W. H. Henson, Jr.: Specific heat of Burley tobacco during the cure; Trans. ASAE 11 (1968) 480-483.

8. Danielson, G. C., and P. H. Sidles: Thermal diffusivity and other non-steady-state methods; in Thermal conductivity, edited by R. P. Tye, Academic Press, New York, N.Y., 1969.

9. Locklair, E. E., W. D. Galloway and M. Samfield: The thermal diffusivity of tobacco; Tob. Sci. 28 (1957) 28-32.

10. Ford, R. M., and W. K. Bilanski: Thermal diffusivity of alfalfa stems; Trans. ASAE 12 (1969) 249251. 
11. Barthakur, N. N.: Heat transfer studies of leaves by microwave radiation; Int. Commun. Heat Mass Transfer 14 (1987) 477-485.

12. Barthakur, N., and J. Tomar: Thermal diffusivity measurements of apples by microwave radiation; $\mathrm{J}$. Microwave Power and Electromagnetic Energy 23 (1988) 39-43.

13. Barthakur, N. N., and N. P. Arnold: Thermal-response characteristics of tobacco leaf exposed to microwave radiation; Beitr. Tabakforsch. Int. 14 (1989) 171-176.

14. Anonymous: Le tabac au Quebec; Agdex 181, Conseil des Productions Végétales du Quebec, Agriculture Quebec, 1987.

15. Barthakur, N. N. : Use of microwave radiation to study plant-environment interactions; J. Microwave Power 10 (1975) 441-449.

16. Luikov, A. V.: Analytical heat diffusion theory; Academic Press, New York, N.Y., 1968.

17. Knight, R. O.: The plant in relation to water; Heinemann Educational Books Ltd, London, 1967.

18. Bolz, R. E., and G. L. Tuve: in CRC handbook of tables for applied engineering science; The Chemical Rubber Company, Boca Raton, Florida, 66$75,1970$.
Acknowledgement

This work was supported by the grant number OGP0010245 from the Natwral Sciences and Engineering Research Council of Canada.

Addresses of authors:

N. N. Bartbakwr,

Department of Renervable Resources,

Macdonald College of McGill University,

21,111 Lakeshore Road.

Ste. Anne de Bellevue, Quebec, H9X 1CO, Canada.

N. P. Arnold,

Experimental Farm,

Agriculture Canada,

p. O. Box 1070,

801 Route 344,

L'Assomption, Quebec, JOK 1GO, Canada. 